\title{
Perception of Youth Towards Live-In Relationships in India
}

\author{
Vinita Ghosh ${ }^{1 *}$
}

\begin{abstract}
"A live-in relationship is an arrangement where two unmarried people live together on a long-term basis in an emotionally or sexually intimate relationship" (Gopal, n.d.). Live-in relationships have seen a remarkable rise in the Indian society in the past decade. This rise can be attributed to the changing perception of youth towards live-in relationships, the need to test compatibility before marriage or to establish financial security before marriage. This paper aims to study the current attitude of Indian youth towards heterosexual cohabitation, popularly known as live-in relationships. This paper has tried to understand whether genderbased differences play an important role in the formation of attitudes towards live-in relationships, whether live-in relationships have become a presumption for marriage and if it has taken precedence over the institution of marriage. I constructed a questionnaire to assess the current attitude of youth towards live-in relationships and used the survey method to collect data. According to the results, it can be said that gender-based differences play an important role in the formation of attitudes towards live-in relationships. Although live-in relationships help in assessing compatibility before marriage, it has not become a presumption for marriage, so it would be incorrect to say that live-in relationships have become a testing ground for marriage. The results also indicate that live-in relationships have not taken precedence over marriage.
\end{abstract}

Keywords: Live-In Relationship, Gender-Based Differences, Cohabitation, Marriage, Attitude, Youth

I

ndia is gradually opening its doors to western cultures and lifestyles. Nowadays not everyone wants to be entangled in the responsibilities of marriage, as a result of which people are exploring alternatives to marriage. In recent times, live-in relationships have emerged as substitutes of marriage as it avoids the obligation of a traditional marriage. A live-in relationship is an arrangement where an unmarried couple lives together for a long time which resembles a marriage. In other words, it is cohabitation. "Cohabitation is defined as an intimate sexual union between two unmarried partners who share the same living quarter for a sustained period" (Bacharach, Hindin and Thomson, 2000, as cited in Saini, 2018). The rise in cohabitation represents one of the most significant changes in union formation patterns in India. "The increase in cohabitation has occurred alongside other major demographic shifts, including rising levels of divorce, delay in marriage, and childbearing" (John and Coast, 2009, as cited in Saini, 2018).

\footnotetext{
13rd Year, Department of Psychology, Loreto College, Kolkata, India *Corresponding Author
} 
The number of people cohabiting together is increasing remarkably in the metro cities. This change is evident from the various court verdicts which provide legal recognition to these couples. In a society where relationships between unmarried males and females are not easily acceptable, the Indian Evidence Act states that long cohabitation is a presumption of marriage. ${ }^{2}$ In a landmark judgment on April 13, 2015, the Supreme Court ruled that couples in live-in relationships will be presumed legally married (Firstpost 2015, as cited in Titzmann, 2017). Despite such progressive judgments, there is a polarization in our society regarding the legitimacy of live-in relationships. In our society marriage continues to be a sacred concept. One exception would be the initiative "Vina Mulya Amulya Seva", which attracted nationwide attention. Natubhai Patel founded a non-profit organization in Ahmedabad, intending to create marital or live-in relationships among elderly singles. Due to the social importance of marriage, unmarried couples often lack the support of their families. Live-in relationships directly affect the status of wife, children, and family. In a collectivist country like India, where non-marital cohabitation is not popularly accepted, opting for a live-in relationship may lead to the disintegration of familial ties in a young person's family. According to Rataj (2014), this may lead to a decrease in life satisfaction and parent-child conflict may reduce the well-being of parents and adult children. In societies where marriage is recognized as the only moral way of family formation and livein relationships are considered as prohibited, the non-marital cohabiting couple is most probably to be despised for not following the traditional norms. However, the disparity between the social expectations of parents and the relationship choices of young adults do not automatically affect family attachment. In other words, the choice of being in a live-in relationship may not itself result in a decreased number of meetings or a lack of family support, even though it may yield some hesitation in relationships (Rataj, 2014). According to Rataj (2014), being in a non-marital cohabitation may adversely affect the amount of happiness and satisfaction which young couples derive from their relationship with their parents, and may harm their quality of life.

Dr. Ahalya Raghuram, Assistant Professor of Clinical Psychology in Bangalore, says that a couple in a live-in-relationship is especially vulnerable as the partners are under pressure to make the relationship work and also cope with an unkind society and parental disapproval. Separation from one's family, coupled with the insecurity of the relationship, can harm a person's psyche. Recently, the Delhi-based start-up, StayUncle was set up to help unmarried couples renting a room in Indian metro cities (Balachandran 2016, as cited in Titzmann, 2017). Such initiatives have developed in response to increased moral policing and unrelenting resistance to unmarried couples living together within parts of Indian society (Brosius 2013, as cited in Titzmann, 2017).

Research on cohabitation has dramatically increased in the past decade (Smock, 2000, as cited in Saini, 2018). Several studies have been done in comparing cohabitation with marriages. Cohabitation, like marital relationships, involves sharing a household with an intimate partner (Waite \& Gallagher 2000, as cited in Saini, 2018). Previous research generally finds lower levels of commitment and relationship quality among cohabiters relative to married couples (Brown, 2003, as cited in Saini, 2018). Relationship quality has been the focus of numerous studies, of which the majority concludes that married

\footnotetext{
${ }^{2}$ Indian Evidence Act, 1872, Section 114 [Court may presume the existence of certain facts. - The Court may presume the existence of any fact which it thinks likely to have happened, regard being had to the common course of natural events, human conduct, and public and private business, in their relation to the facts of the particular case.]
} 
individuals are more satisfied with their relationship than are cohabiters (Brown \& Booth, 1996; Brown 2003, 2004; Stanley et al., 2004, as cited in Saini, 2018). The chances of divorce are higher for those who have previously cohabited, according to data collected in both the United States and Western Europe (Doyle, 2004, as cited in Feldman, 2012).

Generally, males have a more positive orientation for live-in relationships than females (Malatesh \& Dhanasree, 2018). Bumpass and Sweet in 1990 (as cited in Malatesh \& Dhanasree, 2018) stated that women are more likely to cohabit only once and that too with the person they will eventually marry; men are more likely to cohabit with more partners. The less structured roles may make it more difficult for couples to establish gender roles and the division of labor. The negotiation of new rules and meanings has the potential for greater conflict, but the greater flexibility of roles also leaves room for more rewarding, more egalitarian relationships (Cherlin, 2004, as cited in Saini, 2018). Consistent with these findings, in a recent study, Musick (The Times of India, July 2012) pointed out that the idea that marriage has health and happiness advantages over cohabitation is overrated.

"Placing live-in relationships into a single theoretical construct is difficult. Instead, cohabitation is comprised of multiple institutions, serving different purposes and taking on different meanings for different couples" (Knab \& McLahanan, 2006, as cited in Saini, 2018). Motives for cohabiting may be emotional, economic, or pragmatic reasons, and the levels of commitment and the expectations regarding permanence have been found to differ among couples (Carmichael \& Mason, 1998, as cited in Saini, 2018).

I conducted this research study to bridge the existing gap in the literature in live-in relationships. The research question for this study is: Do gender-based differences exist between males and females towards live-in relationships in India?

The objectives of this study are:

1. To explore whether live-in relationships have become a presumption for marriage.

2. To understand the present social status of live-in relationships in India.

3. To explore whether live-in relationships have taken precedence over the concept of marriage.

\section{METHODOLOGY}

\section{Sample}

I used convenience sampling for this research study. Convenience sampling is a sampling procedure where the researcher selects the person according to their convenience (Singh, 1996). I used convenience sampling because I mailed the questionnaire to those respondents who fulfilled the required criteria for the sample. I sent the questionnaire to 20 respondents through email. The sample consists of 20 young adults between the age group of 25-30. Among these, 10 respondents were males and 10 were females. All the respondents live in metropolitan cities all over India, such as Kolkata, Delhi, Mumbai, Bangalore, Ahmedabad, and Hyderabad. The minimum educational qualification required for participating in this study was graduation. I collected the data in June 2020. The anonymity of the respondents has been maintained throughout the study.

\section{Measures}

I constructed a questionnaire under the supervision of my professor for assessing the attitude of youth towards live-in relationships. The questionnaire asks for the basic demographic details of the respondents. It includes 5 open-ended questions which assess the perception of 
the respondents towards live-in relationships. It includes additional 25 statements where the respondents have to rate them on a scale of 1-5, based on their preferences. These statements give a deeper insight into the attitude of the respondents.

\section{Procedure}

I used the survey method for this research study. I constructed a questionnaire under the supervision of my professor and mailed it to 20 respondents. I interpreted the data after analyzing the open-ended answers of each respondent and their ratings for the 25 statements. I noted down how many respondents agreed to the favorable statements regarding live-in relationships and disagreed with the unfavorable ones. I also noted down the number of respondents who agreed to the negative statements regarding live-in relationships and disagreed with the positive ones. Based on these observations, I analyzed the perception of the respondents towards live-in relationships.

\section{RESULTS}

From the data I collected it can be seen that $75 \%$ of the respondents (refer to figure 1) believe that live-in relationships lead to a better understanding before marriage. Many responses reflected the view that cohabitation helps to test compatibility because while dating, a couple is at their best behavior, it does not give a picture of how they would behave ordinarily under adverse circumstances. Maximum responses held the view that cohabitation may not be the best but definitely helpful in knowing each other since the couple will share the responsibilities of domestic life like married couples although it is important to note that there have been extremely mixed reviews regarding the statement: live-in relationship is a presumption for marriage (refer to figure 2). Hence, the fact that cohabitation is a testing ground for marriage remains a debatable issue.

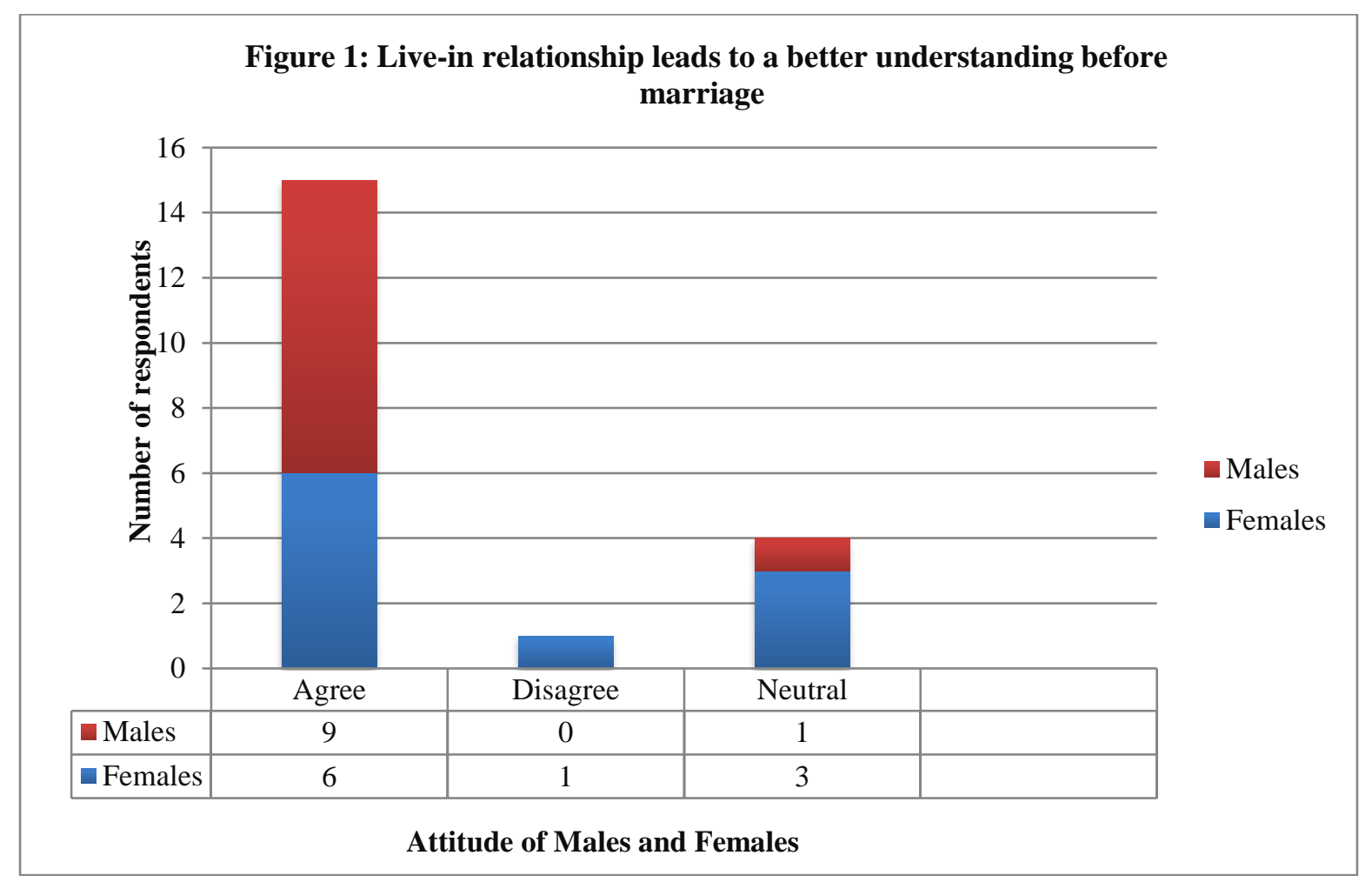




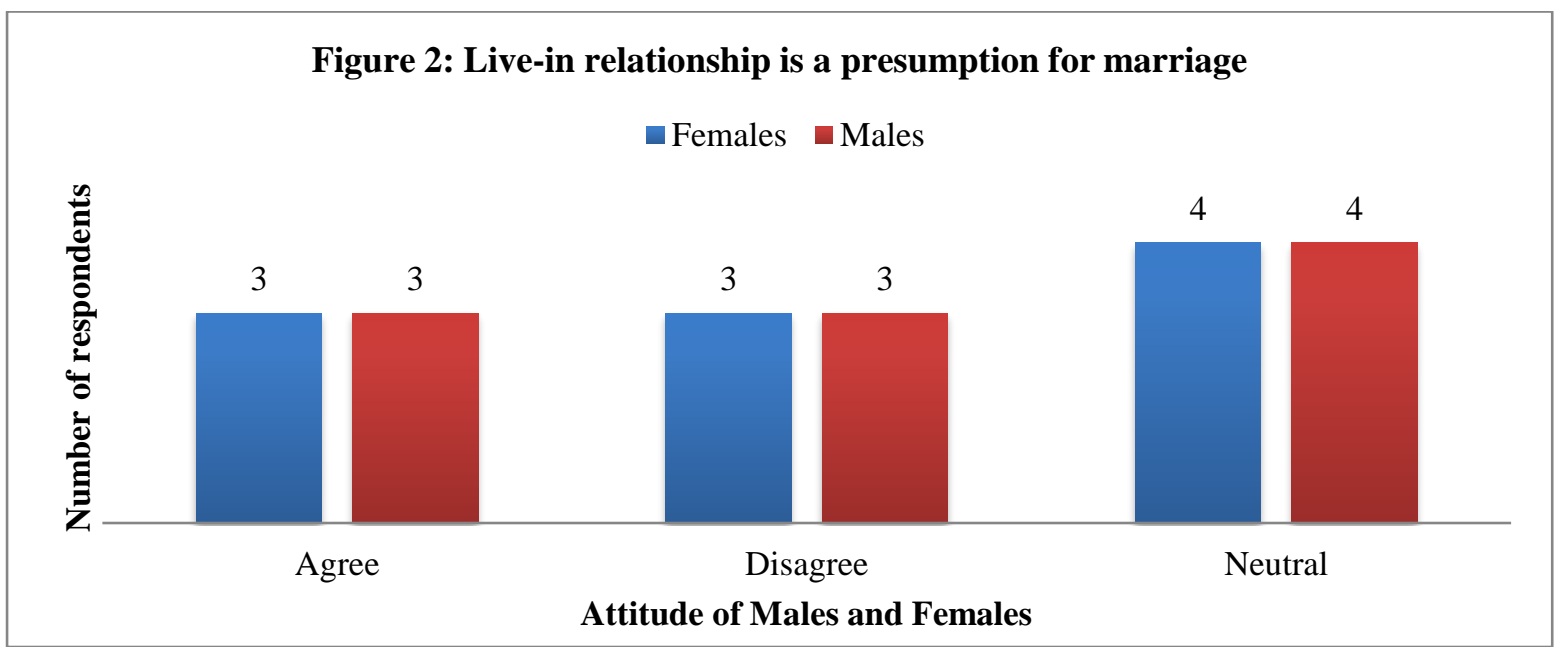

$90 \%$ of males compared to $60 \%$ of females agreed that live-in relationships promote progressive values in Indian society. $45 \%$ of the respondents stated that live-in is against Indian culture. Hence, the perception that cohabitation without marriage is in sync with Indian culture is highly conflicted among the youth (refer to figure 3). Most of the responses have stated that live-in is a taboo according to the Indian society (refer to figure 4). Maximum responses have highlighted the fact that most adults are open to live-in relationships but will think twice before opting for one due to orthodox family values. The effect of social pressure is more or less the same on both genders. However, it is interesting to note that $60 \%$ of females have disagreed with the notion that live-in will negatively affect their relationship with parents compared to only $20 \%$ of males. Both the genders firmly believe that women who opt for live-in relationships face more backlashes from society and are at a higher risk of being exploited. 70 percent of the respondents have agreed to the statement, "there are chances of exploitation of women in live-in relationships due to the absence of a proper law."

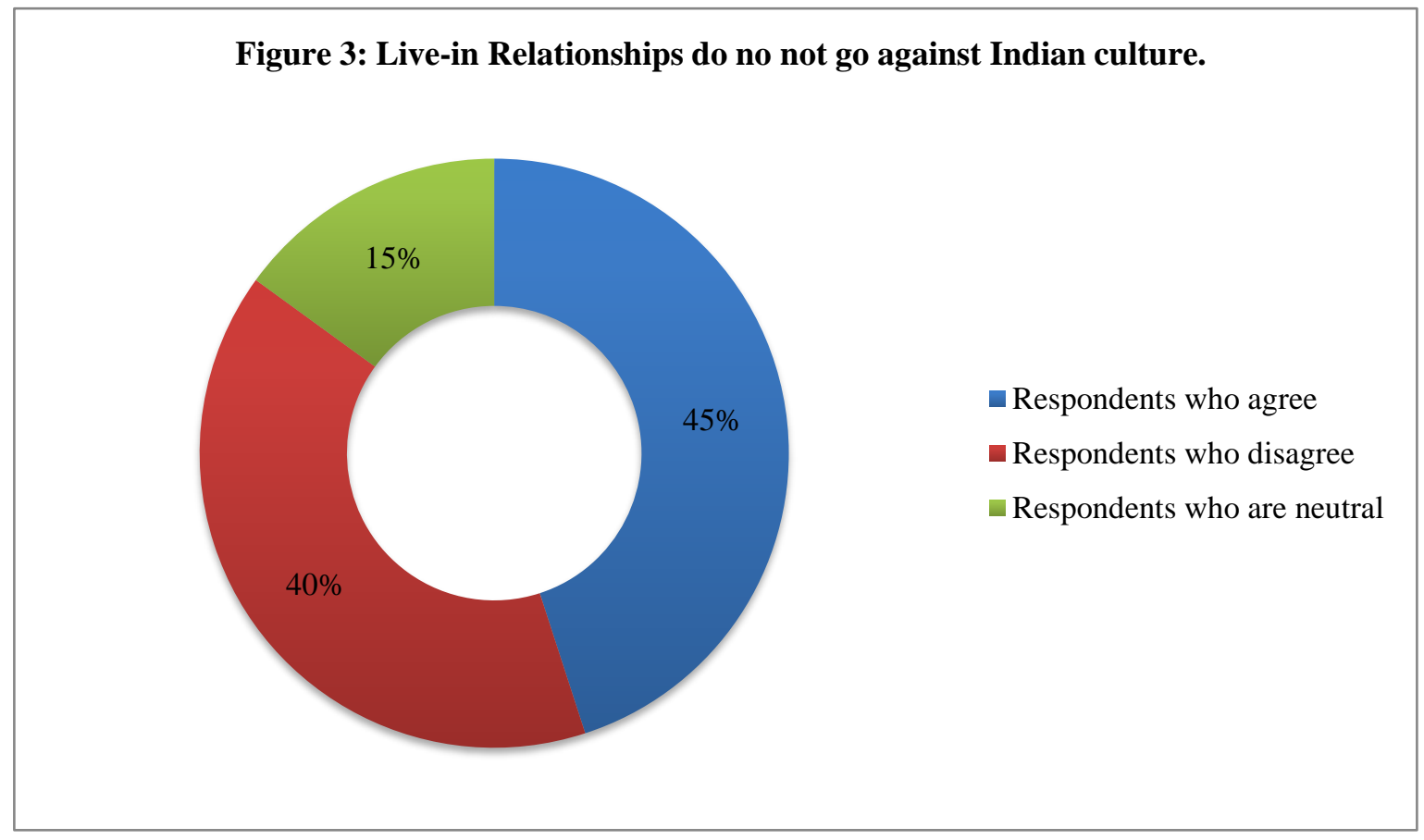




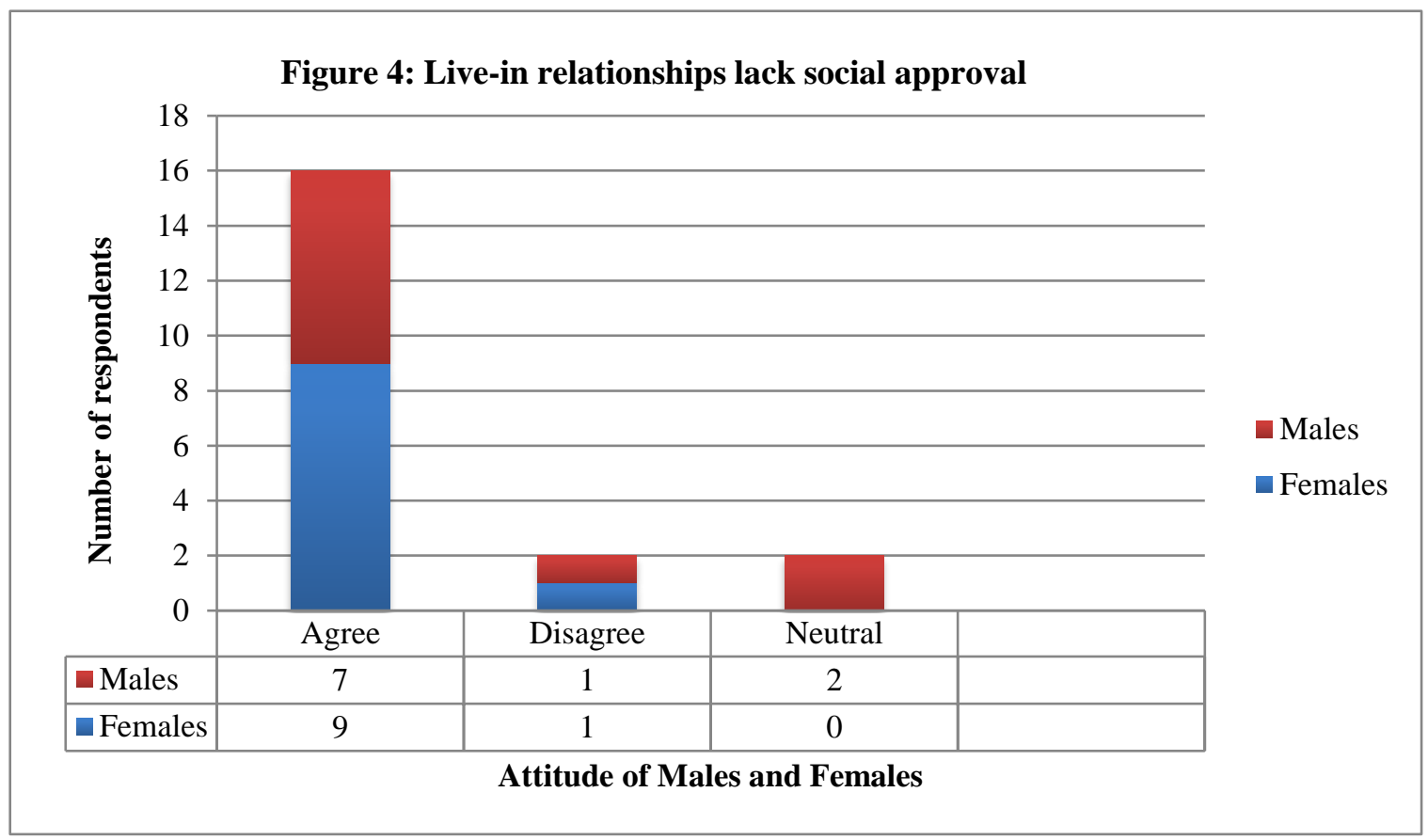

There is a mixed review for the notion that live-in relationships have become an alternative to marriages (refer to figure 5).

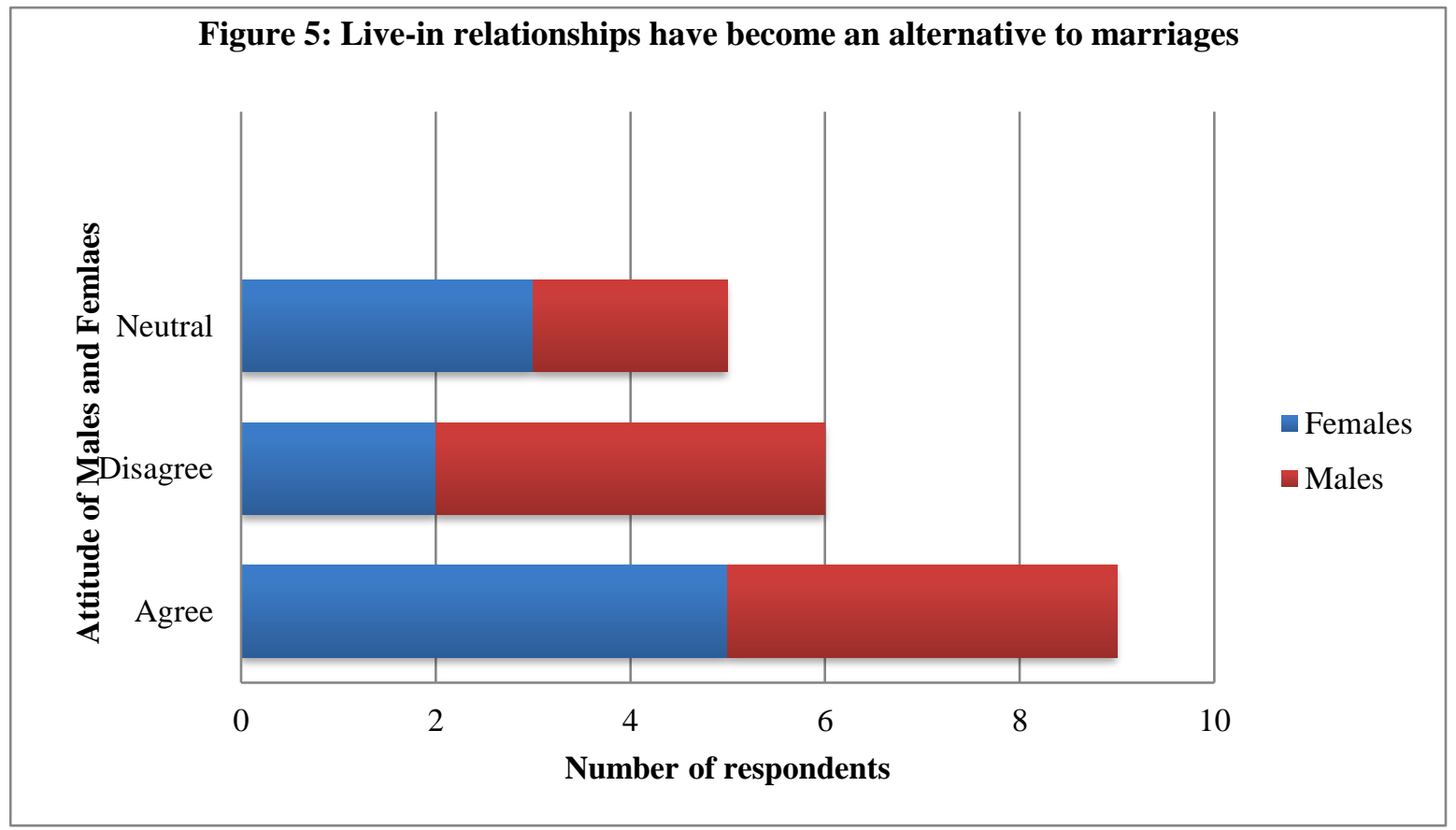

This conflict has always influenced the never-ending contest between marriage and live-in relationship. More than $50 \%$ of men have agreed to the following statements:

- Married people are more dedicated than their live-in counterparts.

- Live-in relationships are more fragile than marriages.

- Live-in relationships are more susceptible to infidelity.

- Live-in relationships lead to bigamous relationships.

- There is higher separation in live-in relationships than in marriages. 
On the contrary, the reactions of women to these statements have mostly been negative or at times neutral. This denotes that maybe women view marriage and live-in in the same light. However, it is interesting to note that $70 \%$ of females have acknowledged that live-in relationships are not as seriously taken as marital relationships. The majority of the participants have stated that live-in has more happiness and health advantage over marriage. Most of the men have also agreed to the following statements:

- Live-in relationships give more emotional support.

- It has less financial burden than marriages.

- It is easier to adjust in live-in relationships.

- Live-in is legally hassle-free.

The responses of females are sharply divided for these statements. This corresponds to the previously mentioned observations that females tend to not differentiate much between livein relationships and marriages. Both the genders equally agree that live-in relationships are not formed to gratify physical needs and children born out of wed locks are more likely to face societal problems. The majority of the respondents have agreed to the statement that live-in relationships can never replace the institution of marriage. Hence, it will be incorrect to say that live-in relationships have taken precedence over marriages.

\section{DISCUSSION}

Both the genders agree that that cohabitation before marriage leads to a better understanding and compatibility but many respondents do not think that live-in is a presumption for marriage. Secondary researches also support this finding. According to a study conducted in the United States by Bumpass and Sweet (1991, as cited in Huang et al., 2012), "Among cohabiting respondents ages 19 to 35 , the most popular reason for cohabitation - endorsed as "important" by $51 \%$ of men and $56 \%$ of women - was: "Couples can be sure they are compatible before marriage." However, according to Huang et al. (2012), "men's approval of cohabitation appears to depend less on marriage plans than women's." According to Bumpass and Sweet (1991, as cited in Huang et al., 2012), a greater percentage of men than women agreed that "It would be all right for me to live with someone without being married even if we had no interest in marriage." Therefore, it can be said that live-in relationships help in testing compatibility before marriage but it is not a presumption for marriage.

The above findings also indicate the gender-based differences in attitudes towards live-in relationship. According to the primary data, women perceive live-in relationships as seriously as marriages as compared to men. Men tend to view marriages in a more serious light. Secondary researches have also supported this claim by stating that women tend to opt for live-in only once and that too with the person whom they are going to marry (Bumpass and Sweet, 1990, as cited in Malatesh and Dhanasree, 2018). According to Huang et al. (2012), "Women see cohabitation as a transitional arrangement preceding marriage, while men tend to see it as a convenient, low-risk way to see if a relationship had longer-term potential, using terms like "test drive" to describe the arrangement." Huang et al., (2012) have also stated that cohabitation represents a greater relationship commitment and greater potential for marriage for women than expressed by men. Although both the genders believe that live-in relationships help in assessing compatibility, women were more likely to analyze their compatibility with their partner through cohabitation in direct relation to marriage. Men were less likely to directly associate cohabitation with marriage. Thus, it can be said that there are marked gender-based differences in the perception between cohabitation and marriage. 


\section{Perception of Youth Towards Live-In Relationships in India}

According to the primary data, both genders have a positive orientation towards live-in relationships but they would contemplate before opting for it because live-in lacks social approval. Both the genders strongly believe that women who opt for live-in receive more flak from society. Secondary researches also support this finding. According to Malatesh and Dhanasree, 2018), the status of women in such a relationship is not that of a wife and lacks social approval or sanctity.

Based on the primary and secondary data, it would be wrong to say that live-in relationships have taken precedence over marriages. Although live-in relationships are becoming popular, marriage remains the preferred alternative for most people. Many perceive marriage as the appropriate culmination of a loving relationship, while others feel it is the "right" thing to do after reaching a particular age (Feldman, 2012). Feldman (2012) has also stated that marriage is preferred because spouses fill many roles, including economic, sexual, therapeutic, and recreational and it is the only fully accepted way to have children.

\section{CONCLUSION AND LIMITATIONS}

The limitation of this study is that concrete generalization cannot be drawn because of the small sample size. It can be concluded that live-in relationships have become popular as a way of keeping away from the restrictions of institutionalized marriages but it faces a lot of resistance from our society. The present study explored the gender-based differences among males and females regarding their perception on live-in relationships. The key findings of the present study revealed that both genders are open to opt for live-in relationships but women tend to view it more seriously than men. Both, the primary and secondary data support the fact that live-in relationships negatively affect the family dynamics. Both, the primary and secondary data have pointed out that the concept, "marriage leads to more happiness" is overrated. After going through both the primary and secondary data, it can be stated that live-in relationships in India can never replace the institution of marriage.

\section{REFERENCES}

Baranowska-Rataj, A. (2014). What Would Your Parents Say? The Impact of Cohabitation Among Young People on Their Relationships with Their Parents. J Happiness Stud, 15, 1313-1332. Retrieved from https://doi.org/10.1007/s10902-013-9477-0

chhibber, M., \& Singh, A. (2015). Live-in relationships: An ethical and a moral dilemma? International Journal of Applied Research, 1(8), 74-77. Retrieved from https://www.allresearchjournal.com/archives/?year=2015\&vol=1\&issue=8\&part=B\& ArticleId $=407$

Chowdhury, A. (2015, July 24). Live-in relationships now acceptable norm in society: SC. Retrieved from Times of India: https://timesofindia.indiatimes.com./india/live-inrelationships-now-aaceptable-norm-in-society-SC/articleshow/48195514.cms

Dholam, S. (2015, February). Socio-legal dimensions of 'live-in relationship' in India. ResearchGate. Retrieved from https://www.researchgate.net/publication/286440123_Sociolegal_dimensions_of_\%27live-in_relationship\%27_in_India

Feldman, R. S. (2012). Discovering the Lifespan (2nd ed.). United States of America: Pearson Education.

Gopal, S. (n.d.). live-in relationship-it's position in India and abroad-pros and conslegitimacy of child-inheritance of property. Retrieved from Legal Service India.com: http://www.legalservicesindia.com/article/211/Live-in-Relationships.html 
Hemalatha, M., \& Banu, N. (2018). Perceptions of Young Adults towards Live - In Relationship. International Journal of Current Microbiology and Applied Sciences, 7(9), 2221-2226. doi:https://doi.org/10.20546/ijcmas.2018.709.274

Huang, P. M., Smock, P. J., Manning, W. D., \& Bergstrom-Lynch, C. A. (2011, February 3). He Says, She Says: Gender and Cohabitation*. Journal of Family Issues, 32(7), 876905. Retrieved from https://www.ncbi.nlm.nih.gov/pmc/articles/PMC3106995/\#R10

Malatesh, G. (2018). Perception of Youth toward Live in Relationship. J Krishi Vigyan, 7(8), 120. doi:10.5958/2349-4433.2018.00172.1

Marriage vs. live-in relationship: Two different approaches to exploring love and companionship. (2019, October 14). Retrieved from https://timesofindia.indiatimes.com/life_style/relationships/love-sex/marriage-vslive-in-relationship-two-different-approaches-to-exploring-love-andcompanionship/articleshow/71582056.cms

Saini, S. (2018). Live in Relationship in India. Journal of Advances and Scholarly Researches in Allied Education, 15(11), 3640. doi:10.29070/JASRAE

Singh, A. K. (1996). Tests, Measurements and Research Methods in Behavioural Sciences. Patna: Bharati Bhavan.

Thakral, C. (2018). Live In Relationship as a new form of Family. Wisdom Crux, 2(11). Retrieved from http://www.wisdomcrux.lawtimesjournal.in/index.php/2018/07/18/live-inrelationship-as-a-new-form-of-family/

Titzman, F. (2017). Contesting the Norm? Live-in Relationships in Indian Media Discourses. South Asia Multidisciplinary Academic Journal, 16. Retrieved from https://journals.openedition.org/samaj/4371

\section{Acknowledgement}

The author(s) appreciates all those who participated in the study and helped to facilitate the research process.

\section{Conflict of Interest}

The author(s) declared no conflict of interest.

How to cite this article: Ghosh V. (2021). Perception of Youth Towards Live-In Relationships in India. International Journal of Indian Psychology, 9(2), 2117-2125. DIP:18.01.209.20210902, DOI:10.25215/0902.209 